\title{
PENGARUH MOTIVASI KERJA DAN DISIPLIN KERJA TERHADAP KINERJA KARYAWAN DENGAN KEPUASAN KERJA SEBAGAI VARIABEL INTERVENING PADA PT ASTRON OPTINDO INDUSTRIES
}

\author{
Bambang Nuryatin \\ Program Studi Magister Manajemen Universitas Tarumanagara \\ bambangn@staff.untar.ac.id
}

Masuk : 07-12-2019, revisi : 23-12-2019 diterima untuk diterbitkan : 23-12-2019

\begin{abstract}
This study aimed to analyse the effect of work motivation and discipline to work performance by job satisfaction as intervened variable at PT. Astron Optindo Industries. Research method that was being used was quantitative method with sample taken based on Slovin. There were 100 respondents. Data analysis technique used Partial Least Square (PLS). Research data was collected by questioner with 5-point Likert Scale as the tool. The result showed (1) work motivation had positive impact to job satisfaction, (2) work discipline had positive impact to job satisfaction, (3) work motivation had positive impact to employee performance, (4) work discipline had positive impact to employee performance, (5) job satisfaction had positive impact to employee performance, (6) job satisfacion had a role as mediated variable between work motivation to employee performance, (7) job satisfaction had a role as mediated variable between work discipline to employee performance. In this research, work discipline had most effect to employee performance.
\end{abstract}

Keywords : Work Motivation, Discipline, Job Satisfaction, Employee Performance

Abstrak : Penelitian ini bertujuan untuk menganalisis pengaruh motivasi kerja dan disiplin kerja terhadap kinerja karyawan melalui kepuasan kerja sebagai variabel intervening pada karyawan PT. Astron Optindo Industries. Metode penelitian yang digunakan adalah metode kuantitatif, dengan teknik pengambilan sampel berdasarkan Slovin. Sampel yang dipergunakan sebanyak 100 responden. Teknik analisis data menggunakan Partial Least Square (PLS). Metode pengumpulan data penelitian dilakukan melalui penyebaran angket dengan menggukan lima poin skala likert sebagai alat ukur. Hasil penelitian menunjukan bahwa (1) motivasi kerja berpengaruh positif terhadap kepuasan kerja karyawan, (2) disiplin kerja berpengaruh positif terhadap kepuasan kerja karyawan, (3) motivasi kerja berpengaruh positif terhadap kinerja karyawan, (4) disiplin kerja berpengaruh positif terhadap kinerja kaaryawan, (5) kepuasan kerja berpengaruh positif terhadap kinerja karyawan, (6) kepuasan kerja berperan sebagai variabel mediasi antara motivasi kerja terhadap kinerja karyawan, (7) kepuasan kerja berperan sebagai variabel mediasi antara disiplin kerja terhadap kinerja karyawan. Dalam penelitian ini disiplin kerja paling berpengaruh terhadap kinerja karyawan.

Kata Kunci : Motivasi Kerja, Disiplin, Kepuasan, Kinerja Karyawan

\section{PENDAHULUAN}

\section{Latar Belakang}

Sumber daya manusia memiliki posisi sangat strategis dalam organisasi, artinya unsur manusia memegang peranan penting dalam melakukan aktivitas untuk mencapai tujuan. Untuk itulah eksistensi sumber daya manusia alam organisasi sangat kuat Ambar Teguh Sulistiyani dan Rosidah (2003). Kinerja dipengaruhi hubungan tak langsung antara kepuasan kerja terhadap motivasi kerja, hal ini didukung hasil penelitian Murti dan Srimulyani (2013) bahwa terdapat hubungan mediasi antara motivasi kerja terhadap kinerja pegawai melalui kepuasan kerja. Kinerja juga dapat dipengaruhi hubungan mediasi antara disiplin kerja terhadap kinerja 
karyawan melalui kepuasan kerja. Menurut Putra dan Landra (2018) bahwa terdapat pengaruh positif disiplin kerja terhadap kinerja karyawan melalui kepuasan kerja.

PT. Astron Optindo Industries merupakan perusahaan dibidang pembuatan kaca mata. Karyawan memiliki peranan yang sangat penting dalam segala aktifitas yang terjadi dalam PT. Astron Optindo Industries, Baik dibagian produksi, pemasaran, distribusi dan yang lain namun menurut Manajer Human Resource Development diketahui tidak sesuai dengan yang diharapkan oleh perusahaan. Karyawan tidak disiplin dan sering terlambat. Selain itu, karyawan juga tidak memberikan kinerja secara maksimal, sehingga target perusahaan tidak dapat tercapai. Karyawan mengeluhkan beban kerja yang berat seiring dengan penambahan produk yang didistribusikan, tetapi perusahaan tidak merekut karyawan baru sedangkan gaji karyawan lama juga tidak dinaikkan, sehingga karyawan merasa tidak puas dengan pekerjaan yang dijalankan. Dari fenomena tersebut, peneliti tertarik untuk melihat hubungan antara pengaruh motivasi kerja dan disiplin kerja terhadap kinerja karyawan melalui kepuasan kerja sebagai variable intervening PT. Astron Optindo Industries.

\section{Tujuan Penelitian}

Tujuan dari penelitian ini adalah untuk mengetahui : (1) Pengaruh motivasi kerja terhadap kinerja karyawan? (2) Pengaruh motivasi kerja terhadap kepuasan kerja karyawan? (3) Pengaruh disiplin kerja terhadap kinerja karyawan? (4) Pengaruh disiplin kerja terhadap kepuasan kerja? (5) Pengaruh kepuasan kerja terhadap kinerja karyawan? (6) Apakah kepuasan kerja berperan sebagai variable mediasi antara motivasi kerja terhadap kinerja karyawan? (7) Apakah kepuasan kerja berperan sebagai variable mediasi antara disiplin kerja terhadap kinerja karyawan?

\section{TELAAH KEPUSTAKAAN Motivasi Kerja}

Hasibuan (2008:143), mendefinisikan motivasi kerja adalah pemberian daya penggerak yang menciptakan kegairahan kerja seseorang agar mereka mau bekerja sama, bekerja efektif dan terintegrasi dengan segala daya upayanya untuk mencapai kepuasan.

\section{Disiplin Kerja}

Mangkuprawira dan Aida (2007:122), kedisiplinan karyawan adalah sifat seorang yang secara sadar mematuhi aturan dan peraturan organisasi tertentu.

\section{Kepuasan Kerja}

Menurut Handoko (1992) dalam Sutrisno (2009:79), kepuasan kerja adalah keadaan emosional yang menyenangkan atau tidak menyenangkan bagi para karyawan dalam memandang pekerjaan mereka.

\section{Kinerja Karyawan}

Menurut Mathis dan Jackson (2006), kinerja karyawan adalah yang mempengaruhi seberapa banyak mereka memberi kontribusi kepada organisasi antara lain termasuk kuantitas output, kualitas output, jangka waktu output, kehadiran di tempat kerja dan sikap kooperatif.

\section{Kerangka Berpikir}

Motivasi kerja, dan disiplin kerja sebagai variabel independent yang mempengaruhi variabel dependen yaitu kinerja karyawan, sedangkan kepuasan kerja sebagai variable intervening.

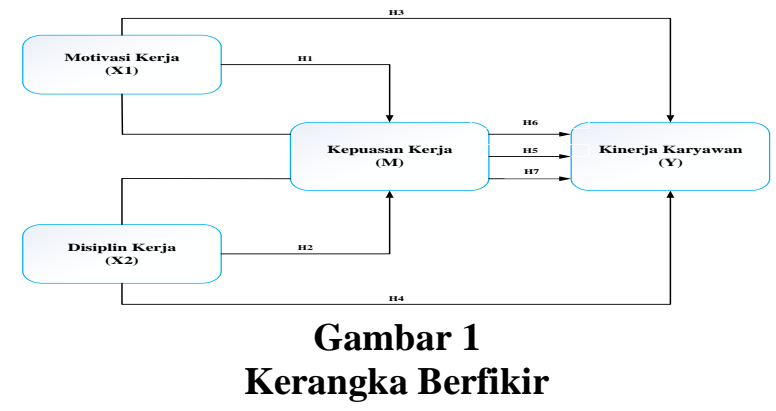




\section{Hipotesis Penelitian}

H1 : Terdapat pengaruh motivasi kerja terhadap kepuasan kerja

H2 : Terdapat pengaruh disiplin kerja terhadap kepuasan kerja

H3 : Terdapat pengaruh motivasi kerja terhadap kinerja karyawan

H4 : Terdapat pengaruh disiplin kerja terhadap kinerja karyawan

H5 : Terdapat pengaruh kepuasan kerja terhadap kinerja karyawan

H6 : Kepuasan kerja memiliki peran dalam memediasi pengaruh motivasi kerja terhadap kinerja karyawan

H7 : Kepuasan kerja memiliki peran dalam memediasi pengaruh disiplin kerja terhadap kinerja karyawan

\section{METODE PENELITIAN}

Jenis penelitian ini adalah kuantitatif dengan pendekatan deskriptif untuk menguji hipotesis dan mengetahui pengaruh variabel bebas (independent) terhadap variabel terikat (dependent) dengan adanya variabel penghubung (intervening) dengan objek penelitian variabel independent yaitu, motivasi kerja, dan disiplin kerja dengan variabel dependen yaitu, kinerja karyawan, sedangkan variabel mediasi adalah kepuasan kerja. Populasi dan sampel pada penelitian ini adalah karyawan PT. Astron Optindo Industries, sebanyak 100 responden. Teknik pengumpulan data menggunakan kuesioner dengan skala Likert sebagai alat ukur. Pengolahan data menggunakan program SmartPLS, pengolahan data terdiri dari evaluasi model pengukura (outer model) dan evaluasi inner model.

\section{ANALISA DAN PEMBAHASAN \\ Evaluasi Outer Model : \\ 1. Uji Validitas}

Pengujian diukur menggunakan nilai convergent validity, Average Variance Extracted (AVE) dan discriminant validity.

\section{a. Loading Factor}

Standar dari pengukuran ini adalah nilai tiap loading $\geq 0.7$ dikatakan ideal

Tabel 1

Output Loading Factor Variabel Motivasi

\begin{tabular}{|c|c|c|c|}
\hline Variabel & Indikator & Nilai Loading Factor & Keterangan \\
\hline \multirow{4}{*}{ Motivasi } & Motivasi 1 & 0.807 & Valid \\
\cline { 2 - 4 } & Motivasi 2 & 0.790 & Valid \\
\cline { 2 - 4 } & Motivasi 3 & 0.742 & Valid \\
\cline { 2 - 4 } & Motivasi 4 & 0.794 & Valid \\
\cline { 2 - 4 } & Motivasi 5 & 0.739 & Valid \\
\cline { 2 - 4 } & Motivasi 6 & 0.749 & Valid \\
\cline { 2 - 4 } & Motivasi 7 & 0.731 & Valid \\
\cline { 2 - 4 } & Motivasi 8 & 0.737 & Valid \\
\cline { 2 - 4 } & Motivasi 9 & 0.832 & Valid \\
\cline { 2 - 4 } & Motivasi 10 & 0.826 & Valid \\
\hline
\end{tabular}

Nilai motivasi > 0,7 yang berarti motivasi berhasil merefleksikan variabel motivasi

Tabel 3

Output Loading Factor Variabel Kepuasan Kerja

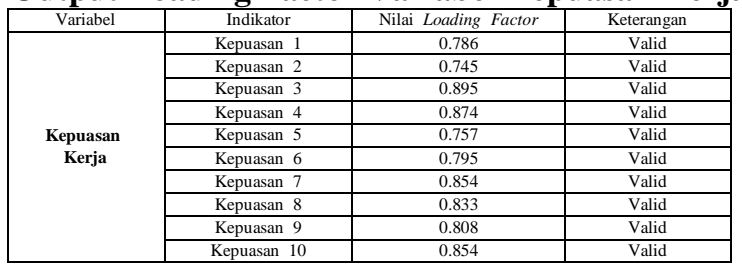

Variabel kepuasan kerja memiliki nilai > 0,7 yang berarti kepuasan kerja berhasil merefleksikan variabel kepuasan kerja

\section{b. Cross Loading}

Variabel indikator terhadap variabel laten harus lebih besar nilainya terhadap variabel laten yang lain.

\section{Tabel 2}

Output Loading Factor Variabel Disiplin

\begin{tabular}{|l|l|l|l|}
\hline Variabel & Indikator & Nilai Loading Factor & Keterangan \\
\hline \multirow{5}{*}{ Disiplin } & Disiplin 1 & 0.807 & Valid \\
\cline { 2 - 4 } & Disiplin 2 & 0.830 & Valid \\
\cline { 2 - 4 } & Disiplin 3 & 0.827 & Valid \\
\cline { 2 - 4 } & Disiplin 4 & 0.819 & Valid \\
\cline { 2 - 4 } & Disiplin 5 & 0.845 & Valid \\
\cline { 2 - 4 } & Disiplin 6 & 0.872 & Valid \\
\cline { 2 - 4 } & Disiplin 7 & 0.866 & Valid \\
\cline { 2 - 4 } & Disiplin 8 & 0.761 & Valid \\
\cline { 2 - 4 } & Disiplin 9 & 0.738 & Valid \\
\cline { 2 - 4 } & Disiplin 10 & 0.800 & Valid \\
\hline
\end{tabular}

Variabel disiplin memiliki nilai > 0,7 yang berarti indikator displin berhasil merefleksikan variabel disiplin

Tabel 4

Output Loading Factor Variabel Kinerja Karyawan

\begin{tabular}{|l|l|l|l|}
\hline Variabel & Indikator & Nilai Loading Factor & Keterangan \\
\hline \multirow{4}{*}{ Kinerja } & Kinerja 1 & 0.719 & Valid \\
\cline { 2 - 4 } & Kinerja 2 & 0.740 & Valid \\
\cline { 2 - 4 } & Kinerja 3 & 0.876 & Valid \\
\cline { 2 - 4 } & Kinerja 4 & 0.864 & Valid \\
\cline { 2 - 4 } & Kinerja 5 & 0.783 & Valid \\
\cline { 2 - 4 } & Kinerja 6 & 0.820 & Valid \\
\cline { 2 - 4 } & Kinerja 7 & 0.845 & Valid \\
\cline { 2 - 4 } & Kinerja 8 & 0.805 & Valid \\
\cline { 2 - 4 } & Kineja 9 & 0.820 & Valid \\
\cline { 2 - 4 } & Kineja 10 & 0.832 & Valid \\
\cline { 2 - 4 } & Kinerja 11 & 0.765 & Valid \\
\hline
\end{tabular}

Nilai variabel kinerja karyawan $>0,7$ artinya indikator kinerja karyawan berhasil merefleksikan variabel kinerja karyawan 
Tabel 5

Output Cross Loading

\begin{tabular}{|l|l|l|l|l|}
\hline & Motivasi & Disiplin & $\begin{array}{l}\text { Kepuasan } \\
\text { Kerja }\end{array}$ & $\begin{array}{l}\text { Kinerja } \\
\text { Karyawan }\end{array}$ \\
\hline Motivasi 1 & $\mathbf{0 . 8 0 7}$ & 0.441 & 0.524 & 0.571 \\
\hline Motivasi 2 & $\mathbf{0 . 7 9 0}$ & 0.400 & 0.515 & 0.533 \\
\hline Motivasi 3 & $\mathbf{0 . 7 4 2}$ & 0.313 & 0.355 & 0.447 \\
\hline Motivasi 4 & $\mathbf{0 . 7 9 4}$ & 0.372 & 0.488 & 0.538 \\
\hline Motivasi 5 & 0.739 & $\mathbf{0 . 3 8 2}$ & 0.372 & 0.424 \\
\hline Motivasi 6 & 0.749 & $\mathbf{0 . 4 0 9}$ & 0.471 & 0.559 \\
\hline Motivasi 7 & 0.731 & $\mathbf{0 . 6 3 9}$ & 0.494 & 0.631 \\
\hline Motivasi 8 & 0.737 & 0.647 & $\mathbf{0 . 5 1 8}$ & 0.632 \\
\hline Motivasi 9 & 0.832 & 0.680 & $\mathbf{0 . 6 5 3}$ & 0.741 \\
\hline Motivasi 10 & 0.826 & 0.687 & $\mathbf{0 . 6 6 5}$ & 0.757 \\
\hline Disiplin 1 & 0.515 & 0.807 & 0.698 & $\mathbf{0 . 6 1 4}$ \\
\hline Disiplin 2 & 0.584 & 0.830 & 0.643 & $\mathbf{0 . 6 4 2}$ \\
\hline Disiplin 3 & 0.567 & 0.827 & 0.657 & $\mathbf{0 . 7 1 1}$ \\
\hline Disiplin 4 & 0.665 & 0.819 & 0.658 & 0.656 \\
\hline Disiplin 5 & 0.642 & 0.845 & 0.604 & 0.624 \\
\hline Disiplin 6 & 0.560 & 0.872 & 0.588 & 0.640 \\
\hline Disiplin 7 & 0.501 & 0.866 & 0.587 & 0.696 \\
\hline Disiplin 8 & 0.475 & 0.761 & 0.532 & 0.594 \\
\hline Disiplin 9 & 0.464 & 0.738 & 0.551 & 0.688 \\
\hline Disiplin 10 & 0.461 & 0.800 & 0.658 & 0.705 \\
\hline Kepuasan 1 & 0.544 & 0.514 & 0.786 & 0.586 \\
\hline Kepuasan 2 & 0.573 & 0.550 & 0.745 & 0.592 \\
\hline Kepuasan 3 & 0.625 & 0.674 & 0.895 & 0.713 \\
\hline Kepuasan 4 & 0.664 & 0.685 & 0.874 & 0.704 \\
\hline Kepuasan 5 & 0.432 & 0.602 & 0.757 & 0.646 \\
\hline Kepuasan 6 & 0.489 & 0.659 & 0.795 & 0.644 \\
\hline Kepuasan 7 & 0.549 & 0.636 & 0.854 & 0.620 \\
\hline Kepuasan 8 & 0.586 & 0.602 & 0.833 & 0.579 \\
\hline Kepuasan 9 & 0.556 & 0.654 & 0.808 & 0.619 \\
\hline Kepuasan 10 & 0.467 & 0.632 & 0.854 & 0.467 \\
\hline Kinerja 1 & 0.662 & 0.580 & 0.609 & 0.719 \\
\hline Kinerja 2 & 0.597 & 0.630 & 0.627 & 0.740 \\
\hline Kinerja 3 & 0.732 & 0.702 & 0.668 & 0.876 \\
\hline Kinerja 4 & 0.674 & 0.679 & 0.628 & 0.864 \\
\hline Kinerja 5 & 0.607 & 0.633 & 0.598 & 0.783 \\
\hline Kinerja 6 & 0.569 & 0.677 & 0.594 & 0.820 \\
\hline Kinerja 7 & 0.621 & 0.694 & 0.595 & 0.845 \\
\hline Kinerja 8 & 0.531 & 0.684 & 0.543 & 0.805 \\
\hline Kinerja 9 & 0.591 & 0.645 & 0.682 & 0.820 \\
\hline Kinerja 10 & 0.659 & 0.666 & 0.666 & 0.832 \\
\hline Kinerja 11 & 0.594 & 0.557 & 0.589 & 0.765 \\
\hline & & & & \\
\hline & & & & \\
\hline
\end{tabular}

Dari Tabel 5, dapat dilihat bahwa :

a. Nilai variabel motivasi lebih besar dari variabel lain

b. Nilai variabel disiplin lebih besar dari variabel lain

c. Nilai variabel kepuasan kerja lebih besar dari variabel lain

d. Nilai variabel kinerja karyawan lebih besar dari variabel lain

\section{c. Fornell-Larcker Criterion}

Akar dari AVE setiap laten variabel harus lebih besar dari korelasi antar variabel laten.

Tabel 6

Output Fornell-Larcker Criterion

\begin{tabular}{|l|l|l|l|l|}
\hline & Disiplin & $\begin{array}{l}\text { Kepuasan } \\
\text { Kerja }\end{array}$ & $\begin{array}{l}\text { Kinerja } \\
\text { Karyawan }\end{array}$ & Motivasi \\
\hline Disiplin & 0.817 & & & \\
\hline $\begin{array}{l}\text { Kepuasan } \\
\text { Kerja }\end{array}$ & 0.759 & 0.821 & & \\
\hline $\begin{array}{l}\text { Kinerja } \\
\text { Karyawan }\end{array}$ & 0.806 & 0.773 & 0.808 & \\
\hline Motivasi & 0.666 & 0.670 & 0.772 & 0.776 \\
\hline
\end{tabular}

Nilai seluruh variabel lebih besar dari latent variable correlation, artinya memenuhi kelayakan evaluasi.

\section{d. Average Variances Exctracted (AVE)}

Nilai AVE > 0,5 ini menunjukkan adanya convergent yang baik.

\section{Tabel 7}

Output Average Variances Exctracted (AVE)

\begin{tabular}{|c|c|}
\hline Variabel & Average Variances Exctracted (AVE) \\
\hline Motivasi & 0.602 \\
\hline Disiplin & 0.668 \\
\hline Kepuasan Kerja & 0.675 \\
\hline Kinerja Karyawan & 0.652 \\
\hline
\end{tabular}

Nilai AVE pada seluruh variabel $>0,5$. artinya seluruh variabel telah memenujhi kelayakan evaluasi AVE.

\section{Hasil Uji Reliabilitas}

\section{a. Composite Reliability}

\section{Tabel 8}

Output Composite Reliability

\begin{tabular}{|l|l|l|l|}
\hline Variabel & Acceptance & Compositei Reliability & Reliability \\
\hline Motivasi & $>\mathrm{i} 0.8$ & 0.938 & Reliabel \\
\hline Disiplin & $>\mathrm{i} 0.8$ & 0.953 & Reliabel \\
\hline Kepuasani Kerja & $>\mathrm{i} 0.8$ & 0.954 & Reliabel \\
\hline Kinerjai Karyawan & $>\mathrm{i} 0.8$ & 0.954 & Reliabel \\
\hline
\end{tabular}

Nilai composite reliability $>0,8$ sehingga variabel motivasi, disiplin, kepuasan kerja dan kinerja karyawan telah reliable

\section{Uji Multikolinearitas (VIF)}

Tabel 10

Output Collinearity Statistics (VIF)

\begin{tabular}{|l|l|l|l|l|}
\hline & Motivasi & Disiplin & Kepuasan & $\begin{array}{l}\text { Kinerja } \\
\text { Karyawan }\end{array}$ \\
\hline Motivasi kerja & & & 1.796 & 2.030 \\
\hline Disiplin kerja & & & 1.796 & 2.634 \\
\hline Kepuasan Kerja & & & & 2.663 \\
\hline Kinerja Karyawan & & & & \\
\hline
\end{tabular}

Nilai $\mathrm{VIF}<10$, maka seluruh variabel tidak memiliki gejala multikolinearitas.
Gambar 2

Average Variances Extracted (AVE)

\section{b. Cronbach's Alpha}

\section{Tabel 9}

\section{Cronbach's Alpha}

\begin{tabular}{|c|c|c|c|}
\hline Variabel & Acceptance & Cronbach's Alpha & Reliability \\
\hline Motivasi kerja & $>0.8$ & 0.927 & Reliabel \\
\hline Disiplin kerja & $>0.8$ & 0.944 & Reliabel \\
\hline Kepuasan Kerja & $>0.8$ & 0.946 & Reliabel \\
\hline Kinerja Karyawan & $>0.8$ & 0.946 & Reliabel \\
\hline
\end{tabular}

Nilai Cronbach's Alpha > 0.8 yang berarti memenuhi nilai yang disarankan. Hasil dari semua uji reliabilitas memperlihatkan bahwa variabel motivasi, disiplin, kepuasan kerja dan kinerja karywan reliable 


\section{Evaluasi Inner Model}

a. $R$-Square $\left(\mathbf{R}^{2}\right)$

Tabel 11

Output R-Square

\begin{tabular}{|l|l|}
\hline & $R$ Square \\
\hline Kepuasan Kerja & 0.624 \\
\hline Kinerja Karyawan & 0.772 \\
\hline
\end{tabular}

Dari tabel 11 dapat diketahui bahwa :

1) Motivasi kerja dan disiplin kerja terhadap kepuasan kerja

Prediksi kepuasan kerja sebesar 0.624 yang apabila terjadi perubahan pada variabel motivasi dan disiplin, maka kepuasan kerja juga akan mengalami perubahan sebesar $62.4 \%$.

2) Motivasi kerja, disiplin kerja dan kepuasan kerja terhadap kinerja karyawan

Prediksi kinerja karyawan sebesar 0.772 artinya apabila terjadi perubahan pada variabel motivasi, disiplin dan kepuasan kerja maka kinerja karyawan juga akan b. $f$-Square $\left(\mathbf{f}^{2}\right)$ mengalami perubahan sebesar $77,2 \%$.

\section{Tabel 12}

Output f-Square

\begin{tabular}{|l|l|l|l|l|}
\hline & Motivasi & Disiplin & Kepuasan & Kinerja Karyawan \\
\hline Motivasi kerja & & & 0.131 & 0.266 \\
\hline Disiplin kerja & & & 0.467 & 0.250 \\
\hline Kepuasan Kerja & & & & 0.097 \\
\hline Kinerja Karyawan & & & & \\
\hline
\end{tabular}

1) Ukuran efek motivasi kerja terhadap kepuasan kerja. Variabel motivasi memiliki pengaruh sedang karena nilai F Square variabel kepuasan kerja sebesar 0.131.

2) Ukuran efek disiplin kerja terhadap kepuasan kerja. Variabel disiplin memiliki pengaruh kuat karena nilai F Square variabel kepuasan kerja sebesar 0.467, variabel motivasi kerja memiliki pengaruh sedang karena nilai F Square variabel kinerja karyawan sebesar 0.266 .

3) Ukuran efek disiplin kerja terhadap kinerja karyawan. Nilai F Square variabel kinerja sebesar 0.250 artinya memiliki pengaruh yang sedang.

4) Ukuran efek kepuasan kerja terhadap kinerja karyawan. Nilai F Square variabel kepuasan kerja sebesar 0.097 artinya memiliki pengaruh yang kecil.

c. Q-Square

Tabel 13

\begin{tabular}{|l|l|l|l|}
\hline & Output Q-Square \\
\hline & SSO & SSE & $\begin{array}{l}\mathrm{Q}^{2} \\
(=1-\mathrm{SSE} / \mathrm{SSO})\end{array}$ \\
\hline Motivasi & 1.000 .000 & 1.000 .000 & \\
\hline Disiplin & 1.000 .000 & 1.000 .000 & \\
\hline Kepuasan Kerja & 1.000 .000 & 615.888 & 0.384 \\
\hline Kinerja Karyawan & 1.000 .000 & 593.903 & 0.460 \\
\hline
\end{tabular}

Nilai $\mathrm{Q}^{2}>0$ (nol) sehingga variabel motivasi, disiplin, kepuasan kerja dan kinerja karyawan memiliki relevansi prediktif.

\section{Pengujian Hipotesis dengan Metode Bootstrapping}

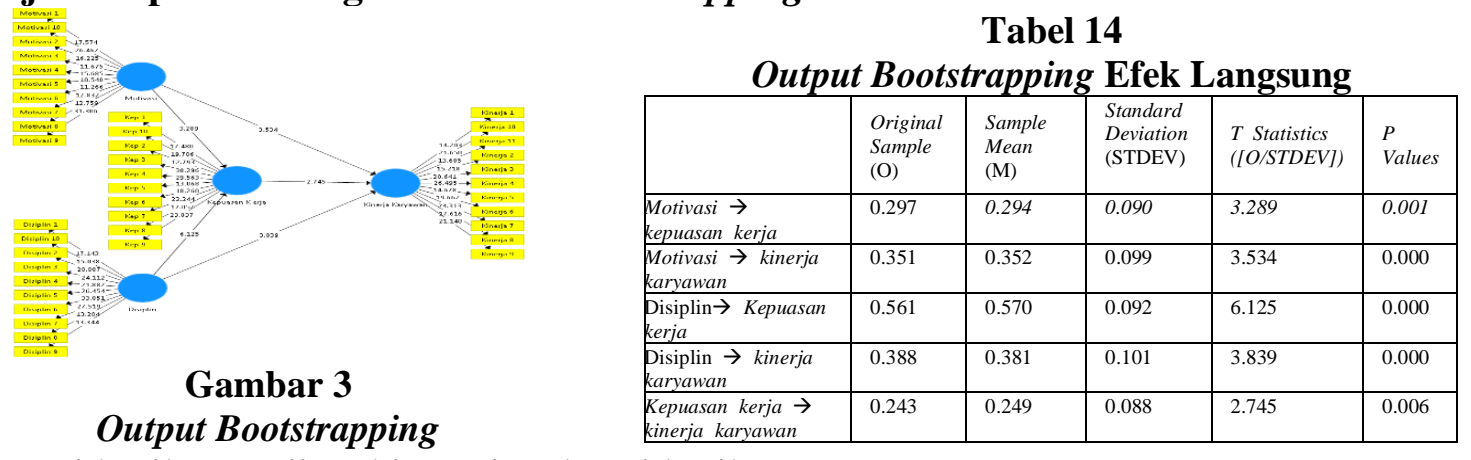

Dari hasil pengujian, hipotesis sebagai berikut : 
a. H1 : Motivasi kerja berpengaruh signifikan terhadap kepuasan kerja karyawan. H1 diterima.

b. H2 : Disiplin kerja berpengaruh signifikan terhadap kepuasan kerja karyawan. H1 diterima.

c. H3 : Motivasi kerja berpengaruh signifikan terhadap kinerja karyawan. H3 diterima.

d. H4 : Disiplin kerja berpengaruh signifikan terhadap kinerja karyawan. H4 diterima.

e. H5 : Kepuasan kerja berpengaruh signifikan terhadap kinerja karyawan. H5 diterima.

\section{Tabel 15}

Output Bootstrapping Efek Tidak Langsung

\begin{tabular}{|l|l|l|l|l|l|}
\hline & Original Sample $(\mathrm{O})$ & Sample Mean $(\mathrm{M})$ & Standard Deviation (STDEV) & $\begin{array}{l}\text { T Statistics } \\
([\text { O/STDEV] })\end{array}$ & P Values \\
\hline Motivasi $\rightarrow$ kep $\rightarrow$ Kinerja & 0.072 & 0.073 & 0.034 & 2.095 & 0.037 \\
\hline Disiplin $\rightarrow$ kep $\rightarrow$ Kinerja & 0.136 & 0.142 & 0.057 & 2.405 & 0.017 \\
\hline
\end{tabular}

Dari hasil pengujian signifikansi dijelaskan hipotesis sebagai berikut :

a. Hasil pengujian variabel motivasi terhadap kinerja karyawan melalui variabel kepuasan kerja memiliki nilai T-Statistics sebesar 2.095, maka H6 diterima.

b. Hasil pengujian variabel disiplin terhadap kinerja karyawan melalui variabel kepuasan kerja memiliki nilai T-Statistics sebesar 2.405, maka H7 diterima.

\section{Pembahasan Penelitian}

Hasil outer model, semua indikator pada variabel yang diteliti valid karena memiliki nilai loading factor > 0,7. Analisis cross loading pada semua indikator variabel berhasil merefleksikan setiap variabelnya. Hasil analisis Fornell-Larcker Criterion disimpulkan bahwa seluruh variabel telah memenuhi kelayakan.

Pengujian reliabilitas dilakukan dengan melihat composite reliability dan nilai hasil pengujian seluruh variabel $>0,8$ yang berarti alat ukut penelitian ini (kuesioner) dapat dipercaya. Dalam penelitian ini tidak terdapat multikolinearitas karena nilai VIF pada seluruh variabel < 10. Dalam evaluasi inner model analisis path coefficient, motivasi secara langsung mempengaruhi kepuasan kerja (positif). Disiplin secara langsung mempengaruhi kepuasan kerja (positif). Motivasi secara langsung mempengaruhi kinerja karyawan (positif). Disiplin secara langsung mempengaruhi kinerja karyawan (positif). Kepuasan kerja secara langsung mempengaruhi kinerja karyawan (positif).

Uji $R$-Square motivasi dan disiplin kerja sebesar 0.624 terhadap kepuasan kerja. Kemudian dapat diketahui bahwa motivasi, disiplin dan kepuasan kerja sebesar 0.772 terhadap kinerja karyawan. Peneliti melakukan analisis $\mathrm{Q}^{2}>0$ yang menunjukkan nilai-niali yang diobservasi sudah direkontruksi dengan baik dan semua variabel memiliki relevansi prediktif.

Hasil pengujian menggunakan bootstrapping menunjukkan bahwa :

\section{Pengaruh motivasi kerja terhadap kepuasan kerja}

Hipotesis pengaruh motivasi kerja terhadap kepuasan kerja berpengaruh signifikan dari nilai t-statistik motivasi sebesar 3,389 dan p-values sebesar 0,001 hal ini sejalan dengan penelitian yang dilakukan oleh Susanto (2019) yang berjudul "Pengaruh Motivasi Kerja, Kepuasan Kerja, Dan Disiplin Kerja Terhadap Kinerja Karyawan Pada Divisi Penjualan PT Rembaka" bahwa motivasi kerja berpengaruh secara signifikan terhadap kinerja karyawan.

\section{Pengaruh disiplin kerja terhadap kepuasan kerja}

Hipotesis pengaruh disiplin kerja terhadap kepuasan kerja berpengaruh signifikan terhadap kepuasan kerja karyawan dengan tingkat keyakinan 95\%. Hal ini sejalan dengan penelitian Winarno dan Sunaryo (2017) yang berjudul "Pengaruh Motivasi, Disiplin dan Kepuasan Kerja Terhadap Kinerja Pegawai" bahwa disiplin kerja berpengaruh secara signifikan terhadap kinerja karyawan.

\section{Pengaruh motivasi kerja terhadap kinerja karyawan}

Motivasi kerja memiliki pengaruh yang signifikan terhadap kinerja karyaan dengan nilai tstatistik sebesar 3,534 dan p-values sebesar 0,000. Sehingga motivasi kerja signifikan terhadap kinerja karyawan. Penelitian Sajangbati (2013) berjudul "Motivasi, Disiplin, dan 
Kepuasan Pengaruhnya terhadap Kinerja Pegawai PT. Pos Indonesia (PERSERO) Cabang Bitung" bahwa motivasi kerja berpengaruh signifikan terhadap kinerja karyawan.

\section{Pengaruh disiplin kerja terhadap kinerja karyawan}

Hipotesis pengaruh disiplin kerja signifikan terhadap kinerja karyawan dengan tingkat keyakinan $95 \%$. Tujuan pendisiplinan yaitu : untuk memperbaiki pelanggaran, menghalangi para karyawan yang lain melakukan kegiatan-kegiatan yang serupa, dan menjaga berbagai standar kelompok tetap konsisten dan efektif sehingga tercapailah kinerja yang lebih baik Suprayitno dan Sukir (2007:24). Penelitian oleh Tinoring, Mediaty (2019) "The effect of work Discipline and Motivation on Work Satisfaction with Employee Performance As Intervening Variables" bahwa disiplin kerja berpengaruh signifikan terhadap kinerja karyawan.

\section{Pengaruh kepuasan kerja terhadap kinerja karyawan}

Kepuasan kerja memiliki pengaruh yang signifikan terhadap kinerja karyawan dengan tingkat keyakinan 95\%. Hasil ini juga mendukung hasil penelitian terdahulu oleh Susanto (2019) berjudul "Pengaruh Motivasi Kerja, Kepuasan Kerja, Dan Disiplin Kerja Terhadap Kinerja Karyawan Pada Divisi Penjualan PT Rembaka" bahwa kepuasan kerja berpengaruh signifikan terhadap kinerja karyawan.

6. Kepuasan kerja memiliki peran dalam memediasi pengaruh motivasi kerja terhadap kinerja karyawan

Kepuasan kerja dapat dijadikan sebagai variabel mediasi dalam pengaruh motivasi terhadap kinerja karyawan. Hal ini sejalan dengan penelitian sebelumnya berjudul "The effect of work Discipline and Motivation on Work Satisfaction with Employee Performance As Intervening Variables" oleh Tinoring, Mediaty (2019) bahwa terdapat pengaruh positif motivasi kerja terhadap kinerja karyawan melalui kepuasan kerja.

7. Kepuasan kerja memiliki peran dalam memediasi pengaruh disiplin kerja terhadap kinerja karyawan

Kepuasan kerja dapat dijadikan sebagai mediasi dalam pengaruh disiplin terhadap kinerja karyawan dan mediasi bersifat partial mediation. Hal ini sejalan dengan penelitian sebelumnya yang berjudul "The Effek of Organizational Culture and Work Disciplin on Employess Performance with Working Satisfaction as Intervening Variabel on CV. Yamaha Waja Motor Denpasar" oleh Putra dan Landra (2018) bahwa terdapat pengaruh positif disiplin kerja terhadap kinerja karyawan melalui kepuasan kerja.

\section{KESIMPULAN}

1. Motivasi kerja terhadap kepuasan kerja karyawan berpengaruh signifikan.

2. Disiplin kerja terhadap kepuasan kerja karyawan berpengaruh signifikan.

3. Motivasi kerja terhadap kinerja karyawan berpengaruh signifikan.

4. Disiplin kerja terhadap kinerja karyawan berpengaruh signifikan.

5. Kepuasan kerja terhadap kinerja karyawan berpengaruh signifikan.

6. Jika karyawan memiliki motivasi yang tinggi dalam bekerja, maka akan meningkatkan kepuasan kerja dalam bekerja.

7. Karyawan yang disiplin akan mudah puas dengan apa yang dikerjakannya, sehingga kinerjanya pun akan semakin meningkat.

\section{SARAN}

1. Hasil penelitian menunjukan bahwa pengaruh kepuasan kerja terhadap kinerja karyawan PT. Astron Optindo Industries cukup rendah, hal ini perlu ditingkatkan oleh pihak manajemen misalnya dengan meningkatkan intesif dan promosi jabatan.

2. Hasil penelitian menunjukan bahwa pengaruh disiplin kerja terhadap kinerja karyawan PT. Astron Optindo Industries cukup tinggi, sehingga perlu dipertahankan bahkan ditingkatkan, misalnya dengan cara menciptakan ruang kerja yang nyaman dan kondusif, dan tidak menghambat karyawan untuk kreatif dalam melaksanakan tugas. 
3. Untuk peneliti selanjutnya disarankan menggunakan bahan rujukan dan teori-teori yang mutakhir, dan penambahan variabel lain.

\section{DAFTAR PUSTAKA}

Ambar Teguh Sulistiyani dan Rosidah, 2003, Manajemen Sumber Daya Manusia, Graha Ilmu: Yogyakarta

Danang, Sunyoto. 2012. Manajemen Sumber Daya Manusia. Jakarta: PT Buku Seru.

Hasibuan, Malayu. 2008. Manajemen Dasar, Pengertian, Dan Masalah. Jakarta: PT Bumi: Aksara.

Kadek Rexy Dewata Putra, Nengah Landra, Agung Eka (2018) The Effek of Organizational Culture and Work Disciplin on Employess Performance with Working Satisfation as Intervening Variabel on CV. Yamaha Waja Motor Denpasar, Jurnal Reserch Analysis : Volume 04 Issue 08 August 2018.

Mangkunegara, A.A (2013) Manajemen Sumber Daya Manusia. Cetakan Kesebelas, Bandung : PT. Remaja Rosdakarya.

Mangkuprawira Shafri dan Aida Vitayala Hubeis. 2007. Manajemen Mutu Sumber Daya Manusia. Jakarta: Ghalia Indonesia.

Mathis, R.L. \& J.H. Jackson. 2006. Human Resource Management: Manajemen Sumber Daya Manusia. Terjemahan Dian Angelia. Jakarta: Salemba Empat.

Murti, H., \& Srimulyani, V. A. (2013). Pengaruh Motivasi Terhadap Kinerja Pegawai Dengan Variabel Pemediasi Kepuasaan Kerja Pada Pdam Kota Madiun. JRMA Jurnal Riset Manajemen Dan Akuntansi, 1(1), 10-17.

Sajangbati, Ivonne (2013) Motivasi, Disiplin, Dan Kepuasan Pengaruhnya Terhadap Kinerja Pegawai PT. Pos Indonesia (Persero) Cabang Bitung. Jurnal EMBA . Vol.1 No.4 : 667678

Suprayitno dan Sukir. 2007. Pengaruh Disiplin Kerja, Lingkungan Kerja dan Motivasi Kerja terhadap Kinerja Karyawan. Dalam Jurnal Manajemen Sumber Daya Manusia, Volume 2 N0. 1. Hal 23-24. Karanganyar: Universitas Slamet Riyadi Surakarta.

Susanto, Natalia (2019) Pengaruh Motivasi Kerja, Kepuasan Kerja, Dan Disiplin Kerja Terhadap Kinerja Karyawan Pada Divisi Penjualan PT Rembaka. AGORA. Vol. 7, No. 1: $1-6$

Sutrisno, Edy.2009. Manajemen Sumber Daya Manusia. Cetakan I. Jakarta: PT. Kencana Media Group.

Tinoring, Mediaty ( 2019) "The effect of work Discipline and Motivaton on Work Satisfaction with Employee Performance As Intervening Variabeles" "The Effek of Organizational Culture and Work Disciplin on Employess Performance with Working Satisfation as Intervening Variabel on CV. Yamaha Waja Motor Denpasar

Winarno, Sunaryo (2017) Pengaruh Motivasi, Disiplin Dan Kepuasan Terhadap Kinerja Pegawai (Studi Kasus Pada Pegawai PT. Anugerah Putra Siantan Songsong Singosari Malang). 